\title{
Corta Luz (2013/2018)
}

\author{
Luiza Peixoto Baldan \\ Doutoranda e mestre em Artes Visuais no PPGAV/EBA/UFRJ. \\ Contato: lbaldan@gmail.com
}

\section{RESUMO}

Corta Luz foi um projeto realizado pela artista Luiza Baldan quando em residência no Pivô/Edifício Copan durante o mês de julho de 2013. O ensaio livre revisitado em 2018 comenta a sua relação com a casa e a rotina no centro novo da capital paulista, focando tanto nos acontecimentos do cenário vertical da metrópole quanto na intimidade dos interiores do prédio, transcendendo a estética dos marcos da arquitetura modernista para deter-se em pormenores do cotidiano local e da urgência dos dias. Como procedimento, a obra e a vida da artista se misturam em uma performance dilatada.

Palavras-chave: Copan, São Paulo, habitar, cotidiano, artes visuais

\section{ABSTRACT}

Corta Luz is a project by artist Luiza Baldan carried out while in residence at Pivô/Copan building during July 2013 and later revisited in 2018. Baldan comments on her relationship with the house and routine in Republica, the so-called new downtown Sao Paulo. She focused on the metropolis' vertical scenery and the intimacy of the building's interiors, transcending the aesthetics of modernist achitecture's milestones. As a procedure, the artist's work and life are mingled in a sort of dilated performance.

Key-Words: Copan, Sao Paulo, inhabit, everyday, visual arts 
A artista carioca Luiza Baldan alugou uma quitinete durante o mês de julho de 2013 no Edifício Copan (SP) e, a partir da relação entre a casa e o ateliê no Pivô, espaço cultural situado no mesmo edifício, desenvolveu o projeto Corta Luz. Voltada para as transformaçôes do centro novo da capital paulista, em parte resultantes de processos de gentrificação e especulação imobiliária, Baldan focou tanto nos acontecimentos do cenário vertical da metrópole quanto na intimidade dos interiores do edifício. Seu olhar transcendeu a estética dos marcos da arquitetura modernista para deter-se em pormenores do cotidiano local. $\mathrm{Na}$ vivência prolongada com aquele espaço e na rotina de inserção progressiva na cidade, caminhando e registrando seu percurso diariamente, a artista incorporou a história, a arquitetura e o contexto do lugar em sua pesquisa. De volta a São Paulo em 2018, desta vez para desenvolver um projeto junto ao MASP, Baldan revisitou o Copan e Corta Luz em pleno auge da conturbação política iniciada justamente durante as manifestaçóes de 2013.

Morei por um curto período em São Paulo e nunca entrei no Louvre, apenas o avistava da janela. Morei por um curto período em Paris e nunca entrei no Louvre, apenas o avistava da janela.

Conheci o Copan através de uma fotografia alemã. Todos estrangeiros, tentando falar alguma coisa sobre a arquitetura moderna brasileira, ou não. Morando ali eu não tinha a noção da imagem famosa do populoso complexo que reúne em 6 blocos 1610 apartamentos porque eu me havia tornado uma unidade autônoma contida na imensidão.
Vivi ali por mais tempo que o entáo dono daquela casa de veraneio invernal no centro novo da capital, que a vendeu logo em seguida da minha partida.

Eu mal conhecia o Ricardo e não fazia ideia de quem eram Keila, Alice, Camila e sabe-se lá quem mais havia passado por ali. Pagava as contas que iam vencer e pronto.

Entrar na casa vazia dos outros me faz especular sobre tudo, duvidar da sujeira, questionar o conteúdo da garrafa de saquê, ter nojo do sabonete em barra. Pelos de desconhecidos, tábua do vaso sanitário de desconhecidos. Tomar banho de chinelo mesmo depois de deixar tudo de molho em cloro. A faxina nunca é profunda demais para tirar os resquícios das vidas passadas. As paredes não deixam esquecer: o reboco em forma de bandeira, pregos e furos por todos os lados. O desenho no chão deixado pelos móveis que há muito não eram movidos do lugar. Redistribuo tudo a meu modo, brinco de casinha como no tempo das bonecas. Invento proveito para objetos que foram deixados no fundo do armário. Dou importância a tudo o que encontro pela frente e guardo novamente no armário o que náo me faz falta, para quem sabe, o próximo inquilino redescobrir a sua utilidade.

Por mais habituada, cada dia o ato de me mudar se torna mais violento. Então a solução é ocupar aos poucos pequenas áreas delimitadas que se expandem com o uso. Ocupar o vacante.

A luz entrava pela sala mas o sol jamais. Ele apenas se insinuava para além da malemolente curva. O amarelo que me chegava vinha refletido 
pelo edifício-garagem-arranha-céu de 31 andares que bloqueava o horizonte. 290 vagas para automóveis bloqueiam um horizonte. No Copan são 221, mas estáo no subsolo e não obstruem a vista de ninguém.

Meu horizonte eram verticais de prédios; janelas que se multiplicavam sem cessar, já que umas se refletiam nas outras entre transparências e interpenetraçóes. Avistava um coração na vidraça vizinha. A leitura dele é a mesma para quem está dentro ou fora, uma maneira eficaz de comunicação entre milhares de pessoas que dividem a mesma quadra triangular. $\mathrm{O}$ coração no Louvre e eu no Copan.

Minha Copancabana inscrita no Guiness Book.

Do hall de elevadores viam-se os cobertores de lá que improvisavam cortinas. Também viam-se quilômetros de tubulaçóes que transportam gases, águas e sons de um lado para outro.

Cortinas cortam a luz, edifícios cortam a luz. Um rebatimento de sol engana a cortina, atravessa a nesga e filtra a parede de azul.

Quando chovia e ventava forte, as pastilhas da fachada caíam como granizo.

É expressamente vedado a qualquer condômino ou titular de direito, ou a quem que, por qualquer título, esteja na posse ou no uso de qualquer unidade autônoma, usar, alugar, ceder, emprestar, no todo ou em parte, para pessoa de vida ou ocupaçáo duvidosa. É expressamente vedado o atendimento de público nas galerias. Estas são medidas que visam garantir a segurança e a valorizaçáo das propriedades, bem como a saúde o sossego e a convivência harmoniosa da comunidade residente.
Garantir a segurança e a valorização das propriedades.

Ao lado da Consolação, Sinatra dizia para voar longe sem contar para a minha máe. 9 de julho na Nove de Julho em 2013. A greve geral me tirava o sono e me embalava num ruído branco que se somava aos táo recorrentes da geladeira, do registro de água, do vento pela janela, das infinitas obras, do caminhão de lixo, do gerador, do ônibus, do alarme dos carros, dos helicópteros sobrevoando a minha cabeça... Um zumbido longínquo, intermitente. Da janela tentei seguir a passeata, mas não podia avistar a rua, apenas moças limpando os vidros, penduradas na fachada sem qualquer proteção, e a bandeira do Brasil, imóvel, sobre a veneziana vizinha.

A bandeira do Brasil em julho de 2013 e em outubro de 2018.

Tirei o colchão do chão e improvisei uma cama. $\mathrm{O}$ frio impregnado por falta de sol se amenizava com uma colcha felpuda e os lençóis amarelos que foram dos meus pais. Transitei entre o Invierno en Lisboa e o inverno em São Paulo. Transito novamente.

Percebo então que não se tratava de uma nova residência, mas de uma internação extrema por tempo determinado. Mesmo estando em uma cidade-mundo que conhecia há tanto tempo, sentia-me desconhecida e estranha, como se fosse a minha primeira visita à cidade grande. A fragilidade de ser alguém pequeno entre torres de concreto distribuídas ao acaso, em um mosaico arquitetônico que faz do céu uma aparição.

Expandia e contraía os caminhos a percorrer, protegida na metrópole da Companhia Panamericana, onde espaço público e privado se misturam. Do aparta- 
mento ao ateliê no Pivô, ambos no mesmo bloco B, bastava pegar um elevador e subir uma escada. $\mathrm{O}$ ateliê, espaço expositivo ativo durante a minha residência no Copan, era uma continuação orgânica da casa habitada, reproduzida em ambientes distintos mas em escala semelhante. Os pregos reapareciam nas paredes e o sofá-cama ficava à disposição dos visitantes.

Deixei o trabalho invadir o espaço.

Rememoro as dificuldades e alegrias das casas que tive até chegar mais uma vez à conclusão de que sou minha própria casa, autônoma do lugar onde me encontro. Para a pauliceia delirante, além de casa, levei afeto. Afeto este que independe da geografia e que atravessa paisagens.

No percurso do elevador até a minha casa, a vizinha do 317 deixava a porta aberta bem na hora do solzão de meio-dia. Tamanha gentileza brilhava sobre o corredor já amarelo e rebatia pelas paredes, cintilando e fazendo a poeira dançar.

Reconhecia o cheiro da casa e não me assustava mais com os barulhos perdidos, com a buzina de navio que era a descarga da vizinha ou com o baticum repetitivo de um apartamento próximo, nem com o porteiro empurrando as contas por debaixo da porta. Gostava até do sabonete em barra. Tive que me registrar na administração do edifício. Acho que até hoje tenho um cadastro de moradora para que, segundo o síndico, todos saibam que eu exista e que, assim, possam me proteger.

Todas as manhãs a rotina se repetia. Ao abrir ligeiramente a cortina, sempre à mesma hora, um senhor baixinho de meia-idade, uniformizado e de boné, estava de pé bem em frente da minha janela, sobre a cobertura daquilo que foi um cinema para 3500 pessoas e que virou uma igreja abandonada. A distância era tão mínima que o funcionário podia praticamente me olhar nos olhos. Eu lhe acenava discretamente com a cabeça e tornava a fechar a cortina.

Em 2013 a Recopa foi do Corinthians. Via as pessoas agasalhadas no manto do Coringão ou vestidas com camisetas oficiais sob os uniformes de trabalho. Tarde da noite e o povo jogando bombas em comemoração à vitória sobre o São Paulo. Meu pai era corintiano, mas nunca simpatizei com o time. Prefiro o Santos e a sua história, talvez por ser alvinegra. Botafoguense e botafogana que sou, recebia no Copan o sinal de uma rede wi-fi chamada Botafogo. A estrela solitária sempre me conduz.

Sambão na República e guerra no Leblon. O som de Se acaso você chegasse entrava pela janela enquanto eu lia as notícias aterrorizantes vindas da minha antiga rua, a Rainha Guilhermina. Ainda imagino o cafofo, a voz de Elza Soares, as pernas de Mané Garrincha, o Botafogo, uma tropa de choque em frente à banca de jornal do Sr. Fernando, o querido alvinegro Cecílio fugindo das bombas de gás pela cozinha do Jobi, a marcha, o golpe, o silêncio.

Sonho feliz de cidade? Cidade de sonho feliz? Feliz cidade de sonho? E Caetano sempre soa táo pertinente. Ele vindo do nordeste e eu do mesmo sudeste, também não entendi nada quando cheguei por aqui. $\mathrm{O}$ papo reto sinuoso, dos anos 70 para cá, mudou pouco. Talvez já me sinta menos estranha do que os versos da canção, mas continuo sem entender o que acontece. Se estamos longe da ditadura pela mudança dos tempos, ainda vivemos dias tenebrosos regidos por arbitrariedades, intolerâncias e truculências; policiais mili- 
tarizados e todo tipo de gentinha que pensa pequeno mas é protegida pelo legítimo poder, e que engorda cofres privados e fulanos internacionais.

Cercada pelo Louvre, Investimento, Hotel Boulevard, Conjunto Zarvos, Ambassador, San Siro e São Luis Plaza, sentia o tiritar da chuva sobre a cobertura do cinema, no mesmo ponto onde via o fantasma do funcionário que me observava pelas manhâs. $\mathrm{O}$ vento que chacoalhava tudo, os plásticos que chiavam, as plantas que dançavam e algumas que tombavam. E quanto mais tempo admirava o arraial de quintais, mais vasos randômicos apareciam. Eram pequenos jardins improvisados, ilhas verdes no meio do cimento, que tentavam levar um pouco de vida para aquela seca selva de pedra atlântica.

Lembro que usava um binóculo emprestado para encarnar o voyeur, mas as lentes de aumento me mareavam, o aparato me incomodava. Minha contemplação da vizinhança não era pessoal, não era invasiva ou intrusa das particularidades alheias. Fazia percursos visuais genéricos, incapazes de descrever os pormenores da vida do outro. Existia qualquer coisa de respeito em mim que me censurava, ou simplesmente o meu interesse estava no monumental coletivo. A minha janela era um orifício da câmara da minha casa, sensível às variaçóes luminosas externas. Só do Louvre eram 368 janelas. Na verdade, o Louvre se chama Pedro Américo, como meu padrinho, o botafoguense. Então, só do Pedro Américo eram 368 janelas. Faltavam 8 que náo conseguia enxergar por conta de um ponto cego. Ver esses retângulos se acenderem ou piscarem com o azul da televisão sempre me pareceu fascinante. Pouco me importava o que os vizinhos faziam no interior de suas casas, mas me alegrava de estarem táo perto, como uma grande família anônima morando em uma caixa única, dividida em caixinhas unitárias, em um quarteirão da grande cidade. Cercada por pessoas de todos os gêneros, cores e classes sociais, me sentia parte de um todo.

$\mathrm{Na}$ época, li uma nota com dizeres de Ravi Shankar: "No dia em que você sentir que o mundo todo é a sua casa, que o céu é seu teto, que a terra é seu piso e que cada árvore é seu jardim, entâo você realmente estará em casa.”. Eu jurava que havia chegado lá.

Decidi buscar na internet os antigos inquilinos da casa que constavam nas contas pagas. Tempos depois só encontrei a Keila, com quem mantive um breve contato à distância após mensagens no Facebook e no Instagram. Sem conhecê-la, sentia um apreço pelo fato de termos morado na mesma casa, por termos cuidado um pouco daquele lar de tantos donos. Keila sem saber virou minha cúmplice, minha comadre.

Incrível era ver que na fachada do Pedro Américo só haviam dois buracos de ar-condicionado. Taparam meio mal e porcamente os outros onze. Sempre apreciei a conformidade das janelas com fundo rosa. Os demais edifícios ao redor também eram bastante homogêneos, porém cinzas tristonhos, janelas retas e secas, ou os pequenos furos de ventilação do San Siro. Já não diria o mesmo dos meus vizinhos copanenses, que faziam da parte dos fundos do prédio um carnaval de adaptaçôes. São poucos os condôminos que prezam pela parte traseira ou pela empena lateral dos edifícios, talvez por pensarem que "ninguém está vendo, então dane-se". E assim, pessoas como eu, vivendo cercadas por partes traseiras e laterais, somos obrigadas a conviver com a feiura ou com a originalidade, dependendo do gosto ou do juízo de cada um. É também aquele momento em que patrimônio tombado esbarra nas necessidades cotidianas de uma vivenda. 
$\mathrm{Na}$ cidadetetris, poucos são os que têm profundidade ou um horizonte possível da Serra da Cantareira.

Arquitetura para uma cidade nova, sem ruína. A mudança do olhar de quem trafega pelas ruas com o afá de mirar para cima para escapar dos prédios, não das montanhas. Penso em Nova Iorque no início do século XX e as imagens que vieram de lá, paisagens verticais, marcos da história da fotografia. Lembro do Copan de Andreas Gursky no início dos anos 2000 e em outras tantas fotos, não só do edifício retratado em demasia, mas de toda a urbanidade de Sáo Paulo.

Vivi temporariamente em um emblema da arquitetura nacional, assinado por quem participou ativamente da construçáo moderna do país, ora aclamado, ora alfinetado pela crítica; homem público com afinidades socialistas, ainda que muitas vezes projetando obras faraônicas pouco condizentes com o popular, com o funcional ou com o igualitário do discurso, mas certamente destaques publicitários das cidades que as abrigam. Vivi em um complexo de vivendas pensado para diferentes estruturas e padróes familiares, no qual a hierarquia se dá na mesma construção, que levando em consideração a posição do sol, o clima e os ventos, deixa os menos favorecidos com a parte mais escura e fria.

Na casa-obra do arquiteto, eu criei a minha. Obra e vida se misturaram em uma performance dilatada, que começava em casa e se alastrava pelo prédio em reflexôes sobre um cotidiano aparentemente bastante conhecido. A obra como um todo não tem um fim em si mesma, é uma experiência recorrente que vai mudando de endereço de tanto em tanto, extraindo matéria de suas próprias dobras. Obra dobra.
Ao atravessar o bequinho do Investimento em direção à São Luis, enfrentando a ventania canalizada na rua de pedestres, olhava ao redor e imaginava o que um dia foi a Vila Normanda. Sentia o Copan pelas costas e imaginava o posto de gasolina. Carros, sempre carros. Em pleno domingo à tarde, grande parte das ruas desertas, com exceção dos carros que jamais deixarão de circular na cidademobil que sempre implora por estacionamentos e garagens automáticas. E quanto mais caminhava, mais percebia as transformaçóes do lugar, seja pelas placas de vende-se, pelos imóveis (re) abandonados ou pelos anúncios dos novos empreendimentos na tentativa de uma outra ocupação residencial e comercial seletiva do centro. Perto dos puticlubs, a Primeira Igreja Presbiteriana Independente tinha apenas um fiel e uma banda que se escutava alto pelo lado de fora. A antiga boate Kilt virou um terreno baldio. A cimentada Praça Roosevelt virou o parque de diversão ilegal dos skatistas insistentes.

A República continua fragmentada entre a graça e o temor do heterogêneo, reunindo o melhor e o pior dos mundos, das diferenças e indiferenças sociais. A retomada do centro traz gente como eu para um centro de todos que pode vir a ser um centro só de alguns. O inóspito só existe para quem quer.

Julho 2013/Outubro 2018 
Série “Corta Luz”, 2013
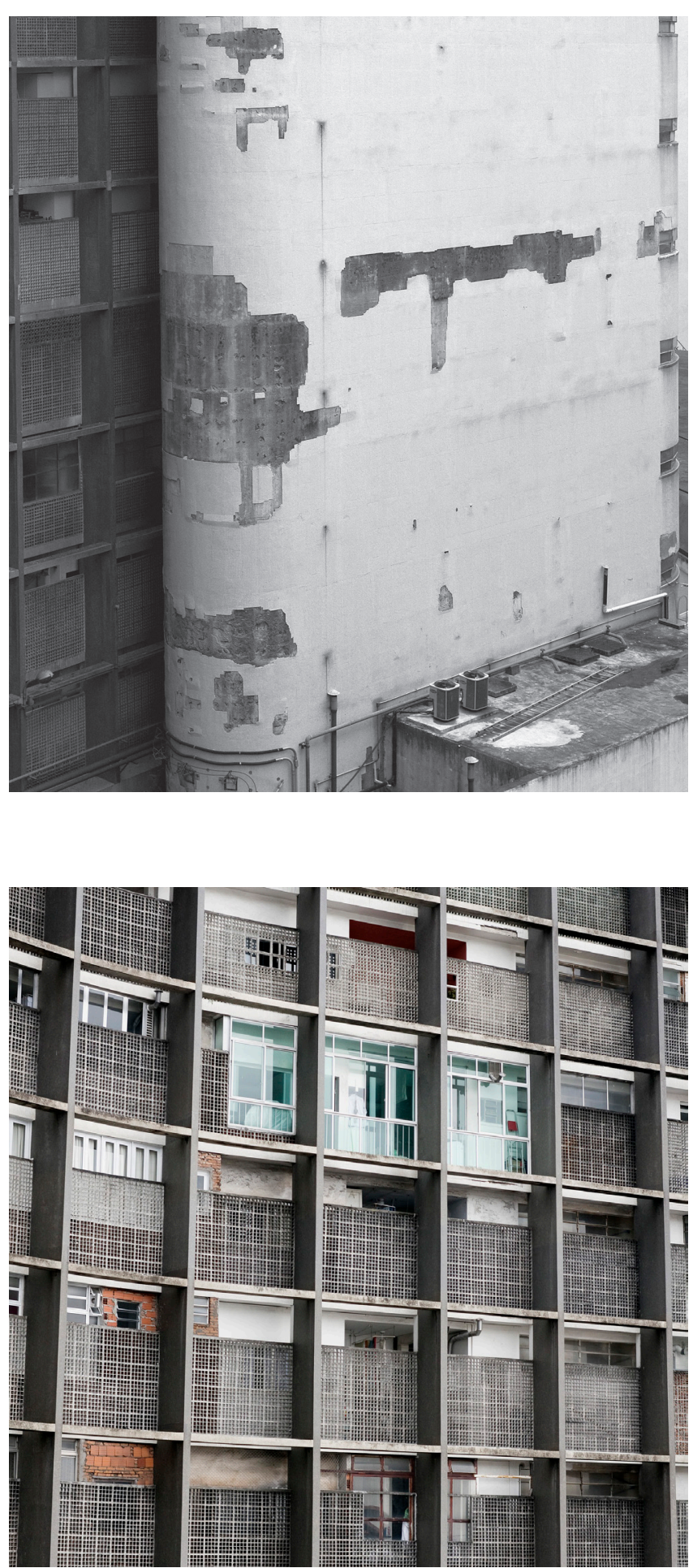

Todas as imagens foram cedidas pela autora.
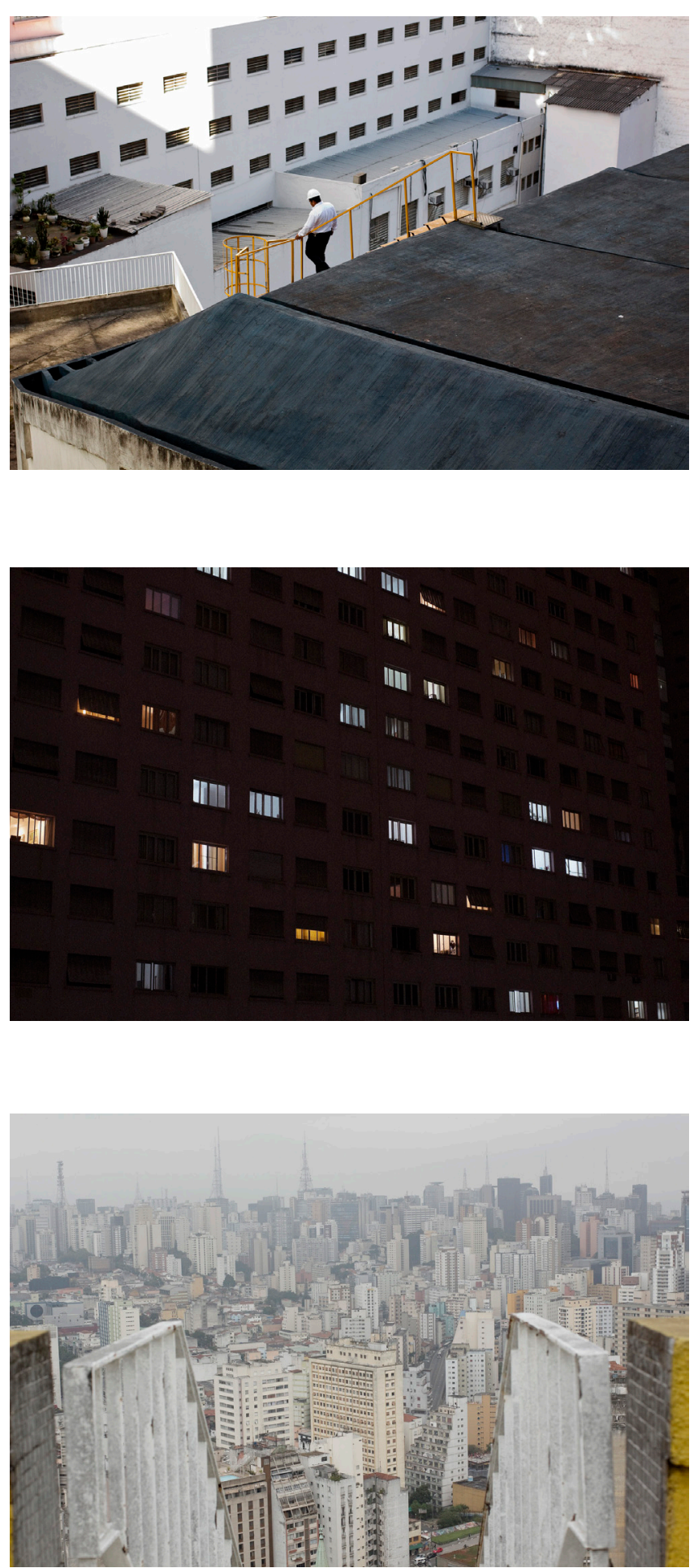

Revista online do Departamento de Arquitetura e Urbanismo da Pontifícia Universidade Católica -

Puc-Rio - Rio de Janeiro Brasil

Ano $4-N^{\circ} 7-$ ISSN 2446-7340 

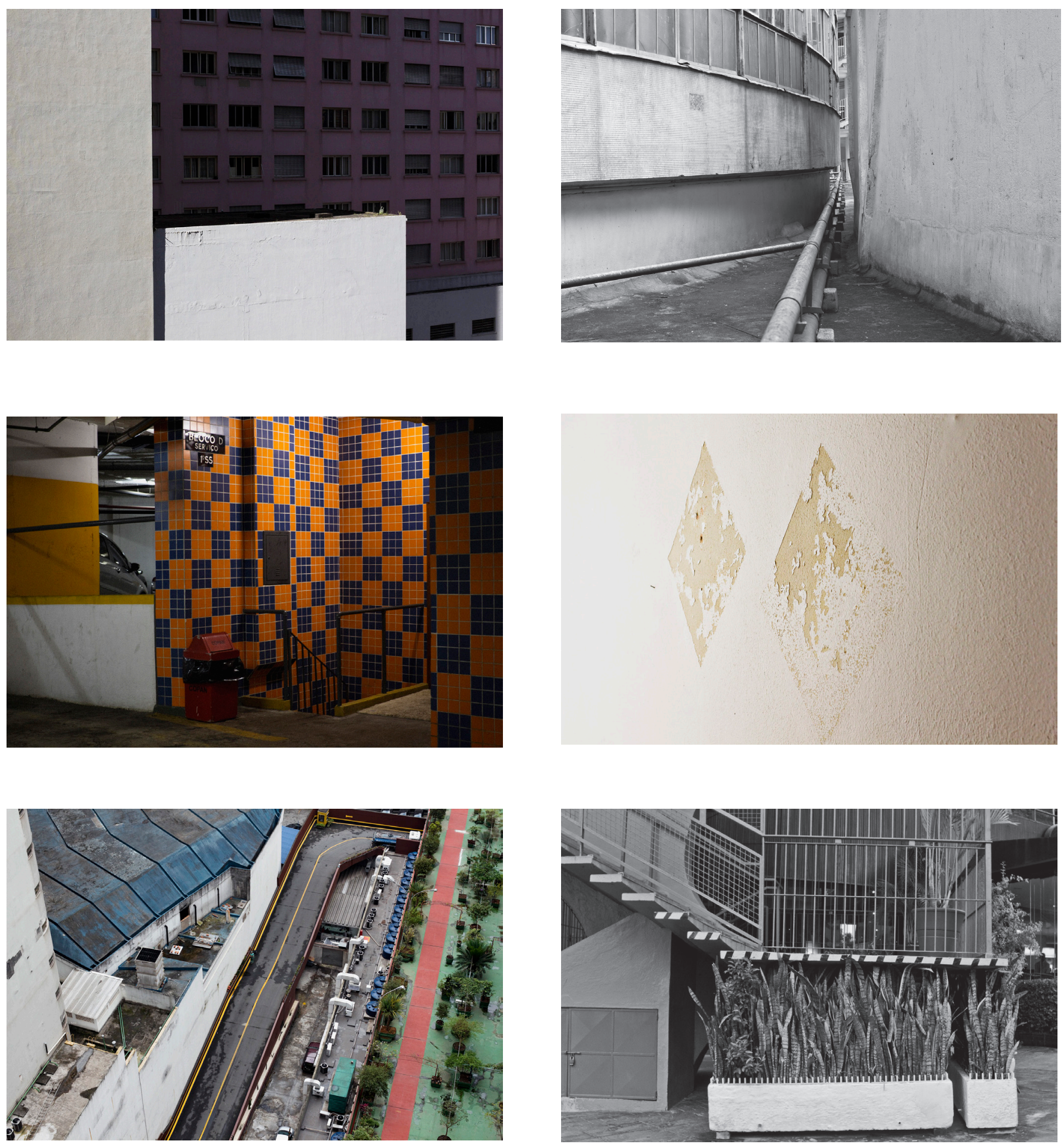

Revista online do Departamento de Arquitetura e Urbanismo da Pontifícia Universidade Católica -

Puc-Rio - Rio de Janeiro Brasil

Ano $4-N^{\circ} 7$ - ISSN 2446-7340 